\title{
Molecular and Metabolic Basis for the Metabolic Disorder Normotriglyceridemic Abetalipoproteinemia
}

\author{
David A. Hardman, Clive R. Pullinger, Robert L. Hamilton, ${ }^{*}$ John P. Kane, ${ }^{\text {ts }}$ and Mary J. Malloy" \\ Cardiovascular Research Institute, "Department of Anatomy, ${ }^{\dagger}$ Department of Medicine, ${ }^{8}$ Department of Biochemistry \\ and Biophysics, and "Department of Pediatrics, University of California, San Francisco, California 94143-0130
}

\begin{abstract}
We have previously described a disorder, normotriglyceridemic abetalipoproteinemia, that is characterized by the virtual absence of plasma low density lipoproteins and complete absence of apoB-100, but with apparently normal secretion of triglyceride-rich lipoproteins containing apoB-48. The patient's plasma lipoproteins were shown on polyacrylamide gels and by antibody mapping to have a new truncated apoB variant, apoB-50, circulating along with her apoB-48. We have found this individual to be homozygous for a single C-to-T nucleotide substitution at apoB codon 2252 , which produces a premature in-frame stop codon. Thus, this is a rare example of homozygous hypobetalipoproteinemia. Electron photomicrographs revealed that the diameters of particles in the $d<1.006 \mathrm{~g} / \mathrm{ml}$ lipoprotein fraction, in both the postprandial and postabsorptive state, are bimodally distributed. The molar ratio of apoE to apoB in these particles is 3.5:1, similar to normal VLDL. The plasma LDL interval contains both spherical and cuboidal particles. Autologous reinfusion of labeled $d<1.006 \mathrm{~g} / \mathrm{ml}$ lipoproteins showed exponential disappearance from plasma, with an apparent halfremoval time of $50 \mathrm{~min}$, somewhat slower than for normal chylomicrons but within the normal range for VLDL. The calculated production rate for apo $B$ was within the normal range in this subject. A very small amount of label was found briefly in the IDL fraction, but none at any time in LDL or HDL. Therefore, because LDL particles that contain apoB-50 lack the putative ligand domain of the LDL receptor, we conclude that the very low level of $L D L$ is due to the rapid removal of the abnormal VLDL particles before their conversion to LDL can take place. (J. Clin. Invest. 1991. 88:1722-1729.) Key words: homozygous hypobetalipoproteinemia $\bullet$ lipoproteins $\bullet$ low density lipoproteins $\bullet \mathbf{L p}$ (a)
\end{abstract}

\section{Introduction}

Chylomicrons, VLDL, LDL, and Lp(a), from human plasma, each contain a high-molecular weight protein component termed apolipoprotein B (apoB). ApoB is an essential structural component of these lipoprotein particles and plays a vital role in the receptor-mediated endocytosis of LDL. ApoB normally exists in two forms designated apoB-48 and apoB-100

Address reprint requests to Dr. David Hardman, Cardiovascular Research Institute, University of California, San Francisco, CA 941430130.

Received for publication 03 April 1991 and in revised form 27 June 1991.

J. Clin. Invest.

(c) The American Society for Clinical Investigation, Inc. $0021-9738 / 91 / 11 / 1722 / 08 \quad \$ 2.00$

Volume 88, November 1991, 1722-1729
(1). In humans, the larger, and normally most abundant form of apoB (apoB-100; apparent molecular mass, $549 \mathrm{kD}$ ), is found principally, if not exclusively, on the lipoproteins of hepatic origin such as VLDL and LDL, and is associated with the transport of endogenous lipids (2). The other, apoB-48 (apparent molecular mass, $264 \mathrm{kD}$ ), is found on the lipoproteins of intestinal origin, the chylomicrons, and is associated with the transport of dietary or exogenous lipids (2). In both liver and intestine, newly synthesized apoB is secreted as a component of triglyceride-rich lipoprotein particles; apoB-48 on chylomicrons from the intestine and apoB-100 on VLDL from the liver. LDL are then formed in a series of metabolic steps from some of the triglyceride-rich apoB-100 particles, but not from apoB-48 particles (2). This pattern is also observed in other animal species, although in rats and mice, apoB- 48 is secreted by both intestine and liver.

Recently, it has been shown, from cDNA sequencing, that apoB-100 is composed of a single polypeptide chain 4536 amino acid residues in length $(3,4)$. Furthermore, apoB-48 arises from the apoB-100 gene as the result of a single nucleotide base substitution in intestinal messenger RNA, resulting in the conversion of a Gln codon (CAA) to a stop codon (TAA) at a point corresponding to amino acid residue 2153 in the apoB sequence (5-7). Thus, apoB- 48 is coded by the apoB- 100 gene and represents the amino terminal 2152 amino acid residues of the apoB-100 sequence.

Previously, we have described a patient (A.F.) with a metabolic disorder that we termed normotriglyceridemic abetalipoproteinemia (8). Other, similar cases have been reported since (9-11). The disorder is characterized by the absence of LDLs and apoB-100 in plasma, with apparently normal secretion of triglyceride-rich lipoproteins containing apoB-48. We subsequently observed that antibodies to the apparent apoB-48 protein from the patient reacted with some determinants in peptides from normal apoB- 100 which are not identified by antibodies raised to apoB-48 from normal individuals. This suggested that in the patient's plasma there might be a truncated form of apoB-100 slightly longer than the normal apoB48 chain. Analysis of the protein by an electrophoretic gel technique of high resolution then revealed a finely spaced doublet. Several truncations of apoB- 100 have now been described in patients with familial hypobetalipoproteinemia $(12,13)$, all due to mutations producing inappropriate stop codons. We have found a unique mutation in the genomic DNA from our patient, which results in production of an apoB-50 protein. We report here a characterization of the lipoprotein particles which bear the abnormal protein and an analysis of their metabolic behavior. This is the first report of homozygous hypobetalipoproteinemia diagnosed at the genomic level.

\section{Methods}

Preparation of lipoprotein fractions. Triglyceride-rich lipoproteins $(d$ $<1.006 \mathrm{~g} / \mathrm{ml})$, IDL $(1.006<d<1.019 \mathrm{~g} / \mathrm{ml})$, LDL $(1.019<d<1.063$ 
$\mathrm{g} / \mathrm{ml})$ and $\operatorname{HDL}(1.063<d<1.21 \mathrm{~g} / \mathrm{ml})$ were prepared by sequential ultracentrifugation (14) from the plasma of a patient (A.F.) with normotriglyceridemic abetalipoproteinemia. To prevent microbial or oxidative degradation of the lipoproteins, we combined the plasma samples with gentamicin sulfate $(0.1 \mathrm{mg} / \mathrm{ml})$, sodium azide $(0.05 \%)$, and EDTA $(0.05 \%$, pH 7.0$)$ immediately after they were obtained (15-17). The three preservatives were present in all solutions that came in contact with the intact lipoproteins. To study the changes induced by fat absorption, lipoproteins were also isolated from plasma obtained $2.5 \mathrm{~h}$ after the patient ingested a liquid meal containing $100 \mathrm{~g}$ of olive oil. Her plasma triglyceride level was $160 \mathrm{mg} / \mathrm{dl}$ at that time.

Studies of reinfusion kinetics. Triglyceride-rich lipoprotein particles were isolated from the patient's plasma and labeled as described previously (18). Briefly, triglyceride-rich lipoprotein particles were obtained by ultracentrifugation at $d=1.006 \mathrm{~g} / \mathrm{ml}$. The particles were labeled with ${ }^{125} \mathrm{I}$ by the iodine monochloride method (19) and were then incubated with the patient's own plasma to reduce the amount of labeled proteins other than apoB by exchange with HDL. The triglyceride-rich particles were then reisolated by ultracentrifugation. All procedures were performed under sterile conditions. Before reinfusion, endotoxins were not detectable by Limulus and by pyrogenicity assays (18). No bacteria were recovered in a culture of the lipoprotein preparation. It was not possible to separate the apoB-50 and apoB-48-containing particles before injection. By inspection of SDS-PAGE gels, at least threequarters of the injected apoB was the apoB- 50 protein. After reinfusion of the labeled particles, samples of plasma were obtained from the patient at baseline and at intervals up to $180 \mathrm{~min}$, and were immediately subjected to sequential ultracentrifugation to separate the lipoproteins into $d<1.006, d=1.006-1.019$, and $d>1.019 \mathrm{~g} / \mathrm{ml}$ fractions. For quantitation of the labeled apolipoproteins the lipoprotein samples were subjected to analytical SDS-PAGE. After fixation and staining the gels were sliced, and the radioactivity of the B-48-50 zone was detected using a gamma spectrometer as described previously (18).

Measurement of lipoprotein particle diameters. Lipoprotein particle diameters were measured from electron photomicrographs using computer-based digitization of 400 individual free-standing particles (20).

Apolipoprotein assays. ApoB, $\mathrm{Lp}(\mathrm{a})$, and apoE levels were determined on plasma and lipoprotein fractions. The apoB was measured by a modified competitive ELISA assay $(21,22)$ using a goat anti-human apoB polyclonal antibody that had been covalently cross-linked to horseradish peroxidase (23). A monoclonal antibody-based ELISA assay (24), specific for $L p(a)$, was used to measure the plasma level of $\mathrm{Lp}(\mathrm{a})$. A radioimmunoassay was used to measure apoE (25).

Purification of $B$ apolipoproteins. Species of apoB were isolated from the triglyceride-rich lipoproteins as described previously using column chromatography followed by preparative SDS-PAGE (26). On preparative SDS-PAGE, a single peak with electrophoretic mobility corresponding to apoB-48 was obtained from the patient. ApoB-48 and apoB-100 were obtained from the triglyceride-rich lipoproteins from subjects with mixed hyperlipemia. The purified apoB proteins were then compared by analytical SDS-PAGE using 4.5-20\% linear gradient slab gels as described previously (26).

Peptide mapping of purified B-proteins. ApoB-48, apoB-100, and the patient's apoB were each subjected to limited proteolytic digestion with elastase in the presence of SDS. Peptides from the resulting digests were analyzed by SDS-PAGE using 4.5-20\% linear gradient slab gels (26). Peptide patterns were revealed by silver stain (27), and by immunoblotting (28) using rabbit antisera against synthetic peptides corresponding to three specific regions of apoB. Antiserum against residues 2129-2144 was kindly provided by Andrew A. Protter (California Biotechnology, Inc., Mountain View, CA). Antisera against residues 2236-2253 and 2272-2292 were kindly provided by Stephen G. Young (Gladstone Foundation Laboratories for Cardiovascular Disease, San Francisco, CA).

Polymerase chain reaction. To ascertain the nature of the mutation responsible for the truncated apoB- 50 variant, predicted by immunoblotting to terminate between amino acid residues 2238 and 2272, we amplified a 1284-bp region of the apoB gene that covers the codons for this section, using the polymerase chain reaction $(P C R)^{1}(29)$. PCR was performed on $200 \mu \mathrm{g}$ of control and patient's genomic DNA in $10 \mathrm{mM}$ Tris- $\mathrm{HCl}, \mathrm{pH} 8.3,50 \mathrm{mM} \mathrm{KCl}, 3 \mathrm{mM} \mathrm{MgCl}, 0.01 \%$ gelatin, $200 \mu \mathrm{M}$ each dNTP, and $20 \mathrm{ng}$ of each oligonucleotide in a total volume of 100 $\mu \mathrm{l}$, using a DNA thermal cycler (Perkin-Elmer Corp., Pomona, CA). Taq polymerase (1.25 U, Cetus Corp., Emeryville, CA) was added after initial denaturation at $95^{\circ} \mathrm{C}$ for $15 \mathrm{~min} .30 \mathrm{PCR}$ cycles were carried out; each cycle was: $1 \mathrm{~min}$ at $95^{\circ} \mathrm{C}, 1 \mathrm{~min}$ at $57^{\circ} \mathrm{C}, 3 \mathrm{~min}$ at $72^{\circ} \mathrm{C}$. The oligonucleotides used were: forward primer, PCR No. 5 (6) (5'CTGAATTCATTCAATTGGGAGAGACAAG3'), 5' end at 6504 bp (cDNA); reverse primer, PCR No. 11 (6) (5'CCAATCAGAAATGTAGGTGACAAG3'), 5' end at 7787 bp (cDNA). Both oligonucleotides were kindly supplied by Dr. James Scott, Medical Research Council Clinical Research Centre, Harrow, UK.

ApoB RFLPs for Xba I (30), Mae I (31), Msp I (32) and Eco RI (30), and the number of $15-b p$ AT-rich tandem repeats in the $3^{\prime}$ hypervariable region (HVR) (33) were determined on the patient's DNA by PCR. For the Xba I RFLP the above PCR product was used. The sequences of the oligonucleotides that were used for the analysis of the other RFLPs and the HVR, and their position in apoB cDNA, are listed below.

For Mae I, 5'GGCTCACATGAAGGCCgAATTCCGAGAG3' (7643-7670) and 5'GCTATGTGGCaAGCTTTCAACAGTGTC ${ }^{\prime}$ (antisense, 8887-8861): for Msp I; 5'GTCATCTACCAAAGGAGATGTCAAGG3' (10607-10632) and 5'GGGAATCAAGGAGTCTTCTGGTTGAG3' (antisense, 11555-11529): for Eco RI; 5'CTCACCATATTCAAAACTGAGTTGAGGG3' (12234-12261) and 5'ATTTGTTCCTCCTCCCCCAAGTTTAGC3' (antisense, 1409514069): for the HVR, 5'GGCACAGCAAAACCTCTAGAACACA T A GTG3' and 5'CCTTCTCACTTGGCAAATAGAATT CCTGAG3'.

The PCR products were electrophoresed on agarose gels, after digestion with the appropriate enzyme, in the case of the RFLPs. The number of repeats in the HVR was calculated from the size, which was determined by comparison with standard DNA fragments.

$M_{13}$ cloning and sequencing. Amplified DNA was digested with restriction endonucleases Pst I and Hind III. A resulting 407-bp fragment was recovered from a $0.7 \%$ low melting agarose gel. This material (60 $\mathrm{ng}$ ) was ligated to $20 \mathrm{ng}$ of Pst I and Hind III digested $M_{13} \mathrm{mp} 18$ and $M_{13} \mathrm{mp19}$. A portion of the ligation mix was used to transform competent $E$. coli DH5 $\alpha \mathrm{F}^{\prime}$. Single-stranded $\mathrm{M}_{13}$ DNA was prepared from plaques and sequencing reactions were carried out with Klenow polymerase and $\left[{ }^{35} \mathrm{~S}\right] \mathrm{dATP}$ using the dideoxy chain termination procedure (34)

FOK I digestion. Portions (240 ng) of control and patient PCR products that had been digested overnight with the restriction endonuclease Fok I were electrophoresed on a $1.5 \%$ agarose slab gel and visualized directly with ethidium bromide.

\section{Results}

Peptide mapping of the patient's apoB. Initially, the patient's apoB was compared to normal apoB-48 by analytical SDSPAGE (Fig. $1 A$ ). Two components were resolved: one that appears to correspond to normal apoB-48 and one that is slightly larger. The larger component was not found in normal subjects, suggesting that it is an abnormal truncated form of apoB similar to those that are responsible for hypobetalipoproteinemia $(12,13)$. The two components could not be separated by preparative SDS-PAGE and it was therefore necessary to perform subsequent protein analysis without further separation.

1. Abbreviations used in this paper: HVR, hypervariable region; PCR, polymerase chain reaction. 


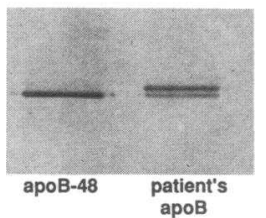

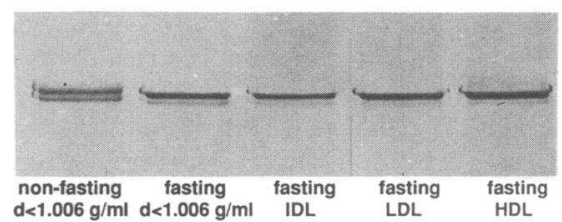

Figure 1. Silver-stained SDS polyacrylamide gels showing $(A)$ a comparison of the patient's apoB and normal apoB-48 isolated from nonfasting $d<1.006 \mathrm{~g} / \mathrm{ml}$ lipoproteins by preparative SDS-PAGE, and $(B)$ total apoB in lipoprotein fractions isolated from the patient. Quantitative distribution of $\mathrm{apoB}$ and $\mathrm{apoE}$ in the same fractions is shown in Table I.

The patient's apoB was next characterized by peptide mapping as described previously (26) (Fig. 2). Fig. $2 A$ shows a silver stained gel comparing elastase digests of apoB-48, apoB-100, and the patient's apoB. The digest of the patient's apoB closely resembles the digest of apoB-48, suggesting that both components of the patient's apoB are structurally related to apoB-48.

In a previous investigation (26), two peptides from elastase digests of apoB-48 and apoB-100 were identified. Peptide $C$ is the carboxyl terminal peptide from apoB-48; peptide $C^{*}$ is the parallel peptide from apoB-100. Peptide $C^{*}$ extends beyond the carboxyl terminus of apoB-48 (7) to the next susceptible elastase cleavage site in apoB-100. However, in the digest of the patient's apoB, a unique peptide $(\mathrm{C \#})$ is present that appears to
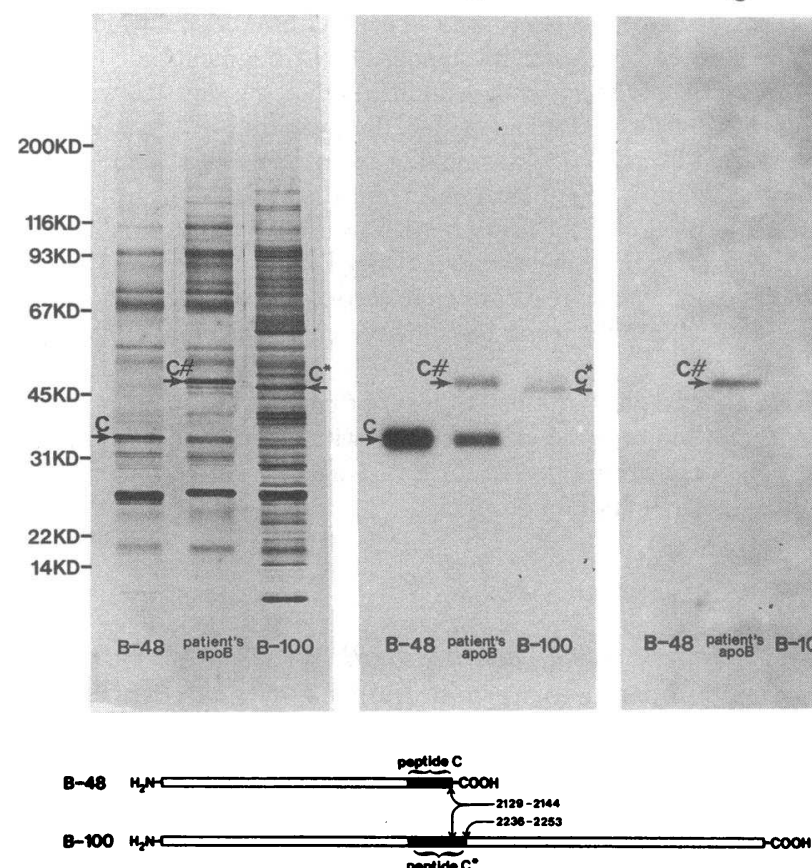

Figure 2. Comparison of apoB-48, apoB-100, and the patient's apoB by one-dimensional peptide mapping. Proteins were subjected to limited proteolytic digestion with elastase and the resulting peptides were separated by SDS-PAGE: $(A)$ silver-stained gel; $(B$ and $C)$ immunoblots of parallel gels using antisera against amino acid residues 2129-2144 and 2236-2253, respectively; $(D)$ diagram showing the position of peptides $\mathrm{C}$ and $\mathrm{C}^{*}$ in intact apoB-48 and apoB-100 (solid bars) and the sequences recognized by the antisera (arrows). be $\sim 12 \mathrm{kD}$ larger than peptide $\mathrm{C}$ and $\sim 1 \mathrm{kD}$ larger than peptide $C^{*}$. By analogy with peptide $C$ from apoB-48, C\# could represent the carboxyl terminal peptide from the larger component of the patient's apoB. To test this hypothesis, immunoblotting was performed using three antisera against synthetic peptides.

Immunoblotting of the digests was performed initially using an antiserum directed against a synthetic peptide corresponding to residues $2129-2144$ in the apoB sequence (Fig. 2 $B)$. This region lies immediately upstream from the carboxyl terminus of apoB-48 (Fig. $2 \mathrm{D}$ ).

In the digest of apoB-48, antiserum 2129-2144 recognized only peptide $\mathrm{C}$; in the digest of apoB-100, the antiserum recognized only peptide $C^{*}$. However, in the digest of the patient's

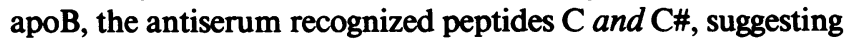
that peptides $\mathrm{C}$ and $\mathrm{C \#}$ are the carboxyl terminal peptides of the two components of the patient's apoB. Thus it would appear that the smaller component of the patient's apoB is apoB48 and that the larger component is a truncated form of $a p o B$ that extends $\sim 12 \mathrm{kD}$ beyond the normal termination site of apoB-48. Thus, the larger component appears to encompass the amino terminal $50 \%$ of apoB- 100 , extending to approximately residue 2258 and is designated apoB-50 using the centile system of nomenclature.

Immunoblotting was then performed using antisera directed against synthetic peptides corresponding to regions upstream (residues 2236-2253) and downstream (residues 22722292) from the predicted carboxyl terminus of apoB-50. Fig. 2 $C$ shows an immunoblot of elastase digests using antiserum against residues 2236-2253 in the apoB sequence. In the digest of the patient's apoB, this antiserum recognized only peptide

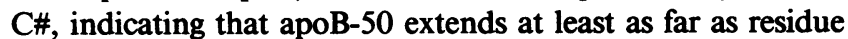
2238. The antiserum did not recognize any peptides in the digest of apoB-48 because residues 2236-2253 are located beyond the normal termination site for apoB-48. Moreover, the antiserum did not recognize any peptides in the digest of apoB-100 even though intact apoB-100 was recognized on dot blots (data not shown). It is possible that the epitope recognized by the antiserum encompasses an elastase cleavage site on apoB-100, and that the epitope is destroyed as a result of elastase digestion. Moreover, based on our subsequent identification of the mutation responsible for the disorder, it is known that the amino acid sequence corresponding to the cleavage site must be present in both apoB-100 and apoB-50, but appears to be susceptible to elastase cleavage only in apoB-100. This could explain the observed difference in molecular weight between peptides, $C^{*}$ and $C \#$.

Finally, using dot blots, we have found that the antiserum against the region beyond the predicted carboxyl terminus of apoB-50 (residues 2272-2292), recognized intact apoB-100, but did not recognize either apoB-48 or the patient's apoB (data not shown), indicating that apoB-50 does not extend beyond residue 2272.

Characterization of genomic DNA from the patient. A 1284bp region of the patient's apoB gene (Fig. 3) that includes the codons for amino acid residues 2238-2272 was amplified using the PCR followed by $M_{13}$ cloning and sequencing. Consistent with the expected homozygous mutation, all of the patient's $M_{13}$ clones that were sequenced were found to contain a single base substitution of a thymine for the normal cytosine at apoB cDNA nucleotide 6963 (35) (Fig. 4). This substitution results in a premature stop codon, TAG instead of the CAG codon for 
APOLIPOPROTEIN B-100 GENE

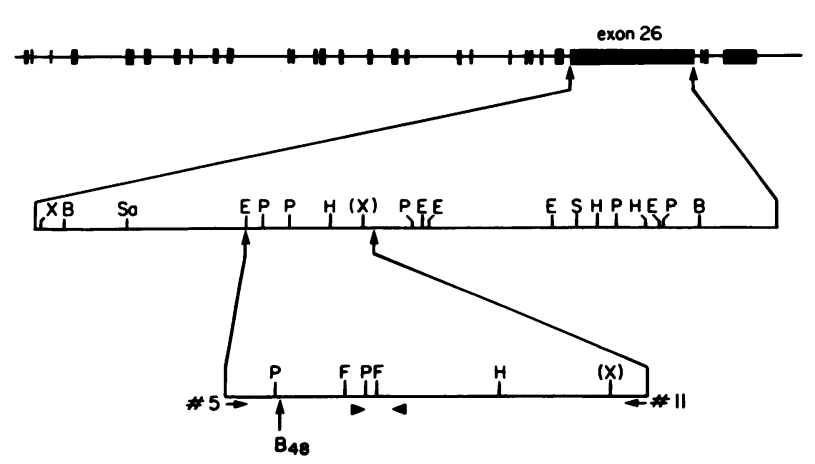

Figure 3. Diagram of the apoB gene showing the restriction enzyme map of exon 26 and the 1284-bp portion of exon 26 that was amplified by the PCR. The position of the codon, which in the mRNA is edited in the intestine resulting in the production of apoB- 48 is indicated as is the region coding for the $\mathrm{COOH}$-terminus of apoB-50 as demonstrated by immunoblotting. $B$, Bam HI; $E$, Eco RI; $F$, Fok I; $H$, Hind III; $P$, Pst I; $S$, Sst I; $S a$, Sal I; $X$, Xba I.

glutamine residue 2252. A predicted protein with 2251 amino acid residues is consistent with the observed apoB- 50 truncated variant. In addition, the $C$-to- $T$ substitution would result in the loss of a Fok I site at that point in the sequence. Control genomic DNA amplified with PCR primers No. 5 and No. 11 when digested with Fok I and electrophoresed on an agarose gel showed the expected 349- and 840-bp bands (Fig. 5). With the patient's DNA the 349-bp band was present, but there was a band of $934 \mathrm{bp}$ and complete loss of the $840-\mathrm{bp}$ band due to loss of the second Fok I site in the 1284-bp PCR fragment (Fig. 3 ). This confirms that the Fok I site is absent from both of the patient's apoB alleles and that she is homozygous for the C-to$T$ mutation, which introduces the premature stop codon.

When the patient's apoB $3^{\prime}$ HVR was amplified only a single band, consistent with 36 tandem repeats, was seen. Using the convention that 2 denotes the presence, and 1 the absence, of a restriction site, the patient had the following RFLP pattern: Xba I (1/1), Mae I (2/2), Msp I (2/2) and Eco RI (2/2).

Particle diameters and content of $a p o B$ and $a p o E$ in circulating lipoproteins. The distribution of particle diameters in photomicrographs of lipoproteins in ultracentrifugal fractions from the patient's plasma are shown in Fig. 6. Particles in the $d<1.006 \mathrm{~g} / \mathrm{ml}$ fraction of plasma in the postprandial and postabsorptive state are spherical. In both cases the diameters are distributed in a bimodal fashion with concentrations at $\sim 300$ and $370 \AA$. There is a small increase in the mean diameter of the particles in the postprandial state. Particles in the IDL fraction are also spherical, and are distributed in a unimodal fashion around a mean of $267( \pm 37) \AA$. The LDL ultracentrifugal interval appears to contain both spherical and cuboidal particles, with a mean of $207( \pm 44) \AA$.

The contents of apoB and apoE in four ultracentrifugal fractions of plasma lipoproteins are presented in Table I. The molar ratio of apoE to apoB in the $d<1.006 \mathrm{~g} / \mathrm{ml}$ fractions is 3.5:1, similar to normal VLDL (Havel, R. J., personal communication). That in the IDL fraction is $1.3: 1$. In the LDL interval the ratio is 1.8:1. However, the appearance of cuboidal particles (Fig. $6 \mathrm{D}$ ), similar to those seen in abetalipoproteinemia, suggests that two populations of particles may coexist in this fraction, one containing apoB-50 and the other a triglyceriderich particle derived from HDL. The distribution of apoB-50 and apoB-48 among the fractions is shown in Fig. $1 \mathrm{~B}$. The abnormal form of $a p o B$ is seen in each of the four ultracentrifugal fractions. Trace amounts of apoB- 48 can be seen in the LDL and HDL fractions.

Concentration of plasma $L p(a)$. Total plasma $L p(a)$ was 0.1 $\mathrm{mg} / \mathrm{dl}$ as determined by ELISA.

Reinfusion kinetics. The content of labeled apoB, preponderantly apoB-50, in the $d<1.006 \mathrm{~g} / \mathrm{ml}$ lipoprotein fraction and in IDL at intervals after autologous reinfusion of labeled $d<1.006 \mathrm{~g} / \mathrm{ml}$ lipoproteins is shown in Fig. 7. On the day of this study, before the reinfusion, the patient's plasma total tri-
A

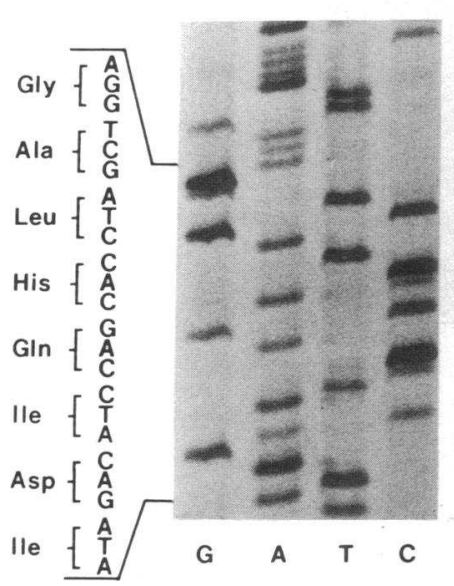

B

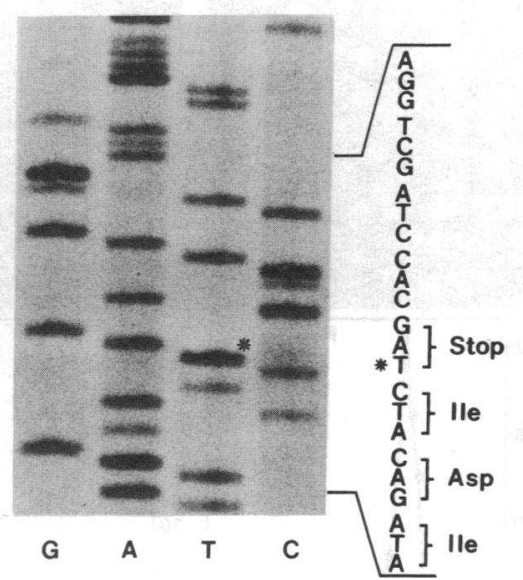

C

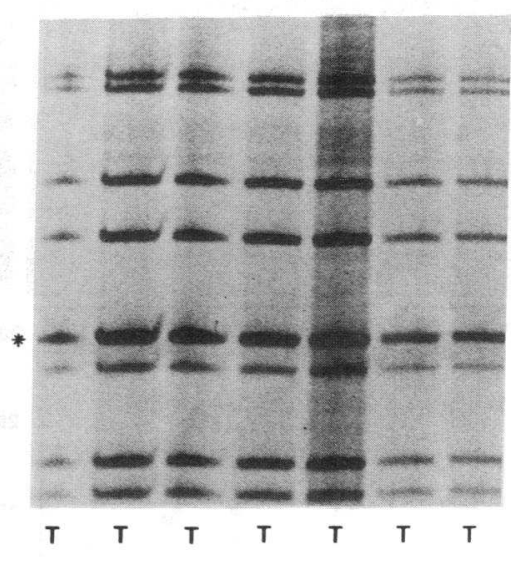

Figure 4. Comparison of autoradiograms of sequencing ladders of DNA from a control subject $(A)$ and from the patient with normotriglyceridemic abetalipoproteinemia $(B)$. The nucleotide marked by the asterisk (6963-cDNA) shows a C-to-T substitution in the patient's DNA, converting $\mathrm{Gln}_{2252}$ to a termination codon. $C$ shows the $\mathrm{T}$ tracks of seven $\mathbf{M}_{13}$ clones prepared from the patient's amplified DNA. The additional $\mathrm{T}$ nucleotide at position 6963 is marked by an asterisk and is present in all seven clones, indicating that the patient is homozygous for the mutation. An additional three clones were examined to determine the sequence of the noncoding strand in the patient's DNA. All of these showed a G-to-A substitution at nucleotide 6963 . 


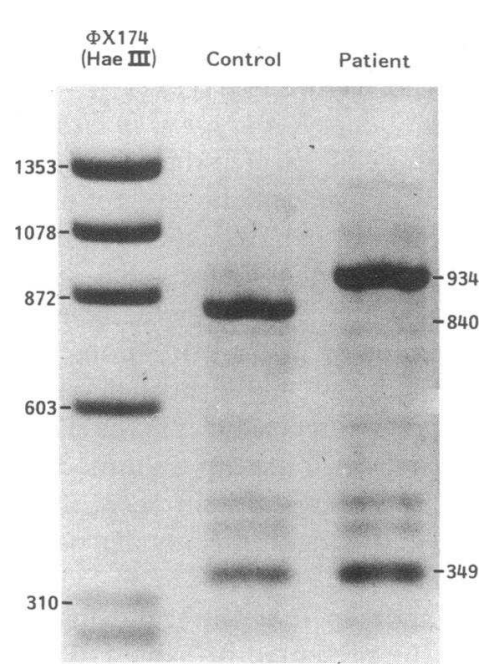

Figure 5. Negative image of an ethidium bromide stained agarose gel of amplified DNA from the patient and a control subject. The DNA had been previously digested with the restriction enzyme Fok I. The loss of the second Fok I site in the patient's DNA, due to the single base C-to-T substitution in the apoB codon 2252, can be seen. That the patient is homozygous for the mutation, which introduces an in frame stop codon and results in the hepatic production of apoB-50, is also evident.

glyceride level in plasma was $32 \mathrm{mg} / \mathrm{dl}$ and total cholesterol was $35 \mathrm{mg} / \mathrm{dl}$. Based on a plasma volume of 3.27 liters calculated from her body weight and hematocrit, $98.5 \%$ of injected label was accounted for in plasma, $1 \mathrm{~min}$ after injection. The disappearance of the label appeared to be exponential with an apparent half-removal time of $\sim 50 \mathrm{~min}$. Label appeared only briefly, at low levels, in the IDL fraction and none was detectable in that fraction after $5 \mathrm{~min}$. No significant counts were detected at any time interval at densities $>1.019 \mathrm{~g} / \mathrm{ml}$.

\section{Discussion}

Normotriglyceridemic abetalipoproteinemia is characterized by a virtual absence of LDL and associated apoB-100 in plasma. Unlike classical abetalipoproteinemia fat absorption is normal and triglyceride-rich lipoproteins are present in the plasma. Originally, these triglyceride-rich lipoproteins were thought to contain apoB- 48 as the sole apoB species (8). How-
Table I. ApoB and ApoE Content in Plasma Lipoproteins after an Overnight Fast

\begin{tabular}{lcc}
\hline \multicolumn{1}{c}{ Ultracentrifugal fraction } & ApoB composition & ApoE composition \\
\hline \multicolumn{1}{c}{$g / m l$} & $m g / d l$ & $m g / d l$ \\
$d<1.006$ & 1.15 & 0.51 \\
$1.006<d<1.019$ (IDL) & 0.05 & 0.01 \\
$1.019<d<1.063$ (LDL) & 0.47 & 0.11 \\
$1.063<d<1.21$ (HDL) & 0.13 & 0.27
\end{tabular}

ever, in the present study we have shown that another apoB species, slightly larger than apoB-48 on SDS-PAGE (270-280 $\mathrm{kD}$ vs. $264 \mathrm{kD}$ for apoB-48) is present, as well as authentic apoB-48. The truncated variant, apoB-50, was shown, using protease digestion and immunoblotting with antisera to synthetic apoB peptides, to terminate between amino acid residues 2238 and 2272. Judging from the complete absence of apoB100 , coupled with the presence of apoB-50, it appears likely that normotriglyceridemic abetalipoproteinemia in the patient A.F. is a homozygous form of familial hypobetalipoproteinemia resulting from a truncation of apoB-100. Consistent with this hypothesis, a single base substitution at apoB cDNA nucleotide 6963 of a $\mathrm{T}$ for a $\mathrm{C}$, converting the codon for residue 2252 to a premature termination codon, was detected in all 10 $\mathbf{M}_{13}$ clones that were sequenced. Gel electrophoresis of Fok I digested apoB DNA confirmed the base substitution, which results in the loss of a site for this restriction enzyme. This procedure also confirmed that the patient was homozygous for the mutation. It was found that the patient was also homozygous for the number of tandem repeats in the apoB $3^{\prime} \mathrm{HVR}$ and all four apoB RFLPs analyzed. Hence, it is unlikely that the mutation occurred twice and it is likely that the homozygosity was due to a consanguineous mating. Because there were no other family members available for study we have not been able to look at the effects of the mutation in the heterozygous state.

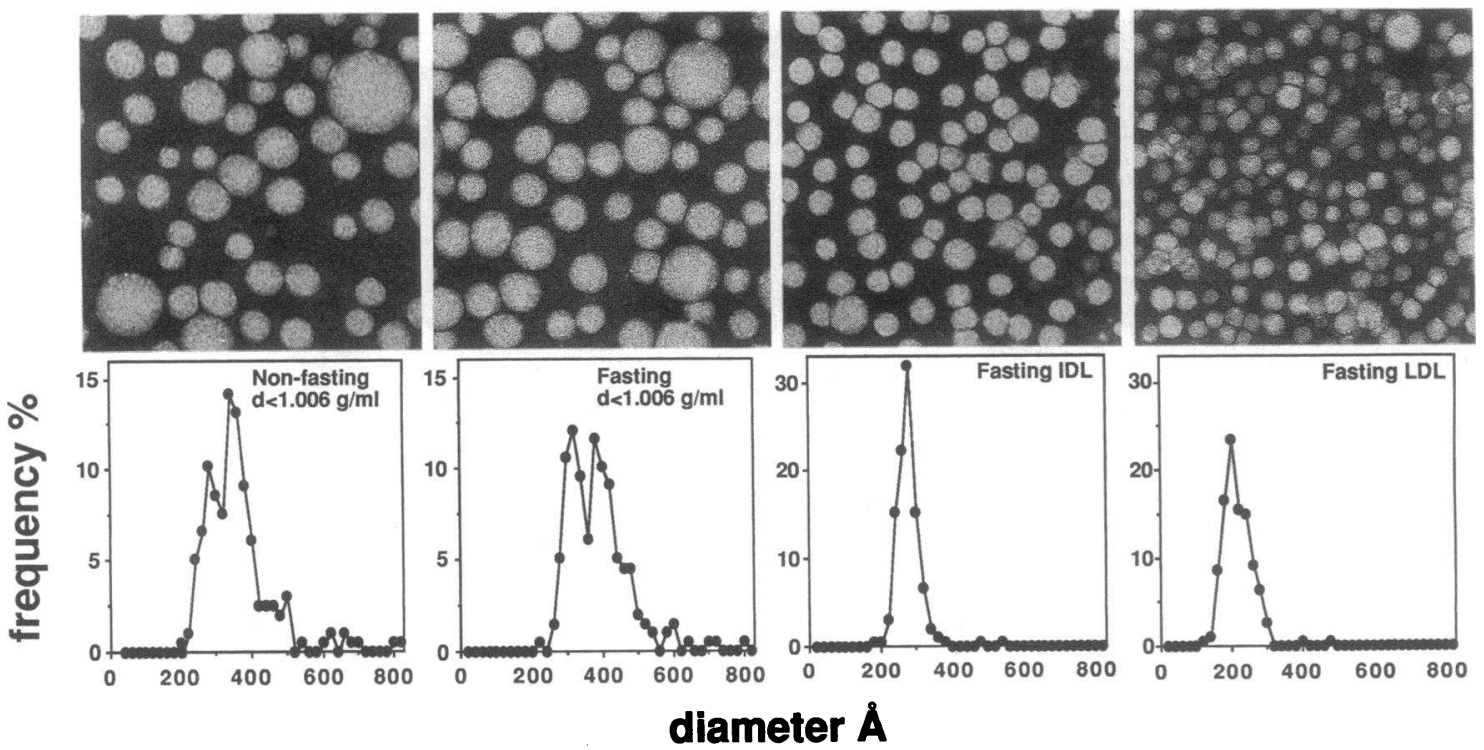

Figure 6. Electron photomicrographs and respective size profiles of lipoprotein fractions prepared from the patient's plasma. Magnification, 108,000 . 


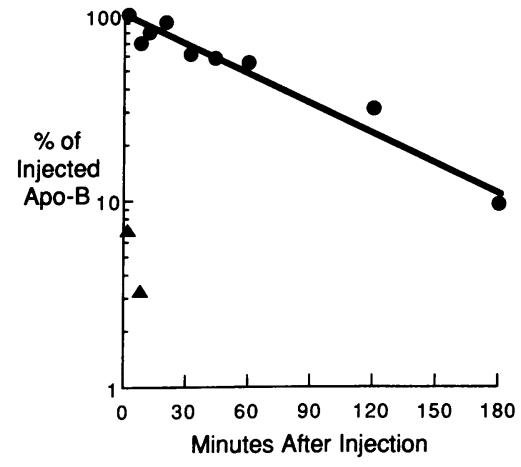

Figure 7. Labeled apoB in the patient's plasma at intervals after injection of labeled $d<1.006$ $\mathrm{g} / \mathrm{ml}$ lipoproteins as a percentage of injected dose. (Circles) $d<1.006$ $\mathrm{g} / \mathrm{ml}$ lipoproteins; (triangles) IDL.

Previous observations with this patient indicate that intestinal absorption of dietary fat is normal and that triglyceriderich lipoproteins containing apoB-48 are present in the plasma (8). Thus, it would appear that the synthesis of apoB-48 and the secretion of chylomicrons by the intestine are unaffected. The presence of apoB- 48 along with apoB- 50 is to be expected because the mutation leading to the production of apoB- 50 is located downstream from the normal termination site for apoB-48. Moreover, the patient's genomic DNA sequence is normal in the vicinity of nucleotide 6666 , which upon editing in the mRNA leads to the production of apoB- $48(5,6)$. Consequently, it would appear likely that apoB-50 is synthesized exclusively by the liver in place of the normal apoB- 100 .

The truncated apoB-50 variant is one of a number that have been reported. All are due to mutations in the apoB gene. These include single nucleotide substitutions $(36,37)$ or deletions (38-43), and deletion of 2 (40), 4 (44), and 37 nucleotides (45). No variants smaller than apoB-31 have as yet been detected in plasma even though DNA mutations that predict shorter variants have been discovered $(38,46)$. This may be because these shorter peptides are not secreted, or likely, because they can be readily expressed and secreted by cultured hepatoma cells (47), they may be cleared very rapidly from the circulation. The longest truncated apoB species reported are apoB-86 (42), apoB-87 (43), and apoB-90 (48). ApoB-90, like normal apoB-100 is present in VLDL and LDL (48). The variants between apoB-31 and apoB-50, including the normal apoB-48 are found in VLDL or HDL, but only at very low levels in LDL. This information points to a domain or domains in the $\mathrm{COOH}$-terminal $50 \%$ of apoB- 100 that may be essential for the formation of stable particles in the LDL density range. The recently reported truncated species, apoB-54.8 (37), apoB61 (45), and apoB-67 (41), will no doubt shed further light on the process of LDL formation.

The present case is the first reported for a homozygous mutation resulting in a truncated apoB and this case of normotriglyceridemic abetalipoproteinemia is a rare example of homozygous hypobetalipoproteinemia. It is interesting that many of the probands in the other reported cases of hypobetalipoproteinemia involving the truncation of apoB have some associated defect that contributes to their low plasma apoB levels. That is, these individuals appear to be compound heterozygotes, with separate mutations leading either to low levels of apoB- 100 together with a truncated apoB variant (45) or in two cases $(40,42)$ two different truncated species of apoB. Whereas individuals with two null apoB alleles are clinically very similar to patients with abetalipoproteinemia, those with one null al- lele and one producing a truncated apoB or those with two alleles both producing truncated $\mathrm{apoB}$ species display a range of clinical features. Those with one allele producing a truncated apoB together with a normal allele often have plasma cholesterol and apoB levels close to or within the normal range. It is therefore likely that many more individuals with truncated apoB species who are not compound heterozygotes or homozygotes are present in the general population than is indicated by the frequency of clinically recognized hypobetalipoproteinemia. Hypobetalipoproteinemia is probably caused by a family of heterogeneous mutations, such as defects in promoters and splice sites in addition to truncations due to premature stop codons.

The preponderance of apoB-50 in the patient's $d<1.006$ $\mathrm{g} / \mathrm{ml}$ lipoproteins suggests that, as with normal individuals, most of these lipoproteins are of hepatic origin. The half-life for removal of $50 \mathrm{~min}$ (somewhat slower than that observed for chylomicrons [18]) is within the range observed for VLDL, in normal humans, at her triglyceride pool size, allowing for the fact that somewhat less than one-quarter of the apoB protein present in the infused lipoproteins was apoB-48. The observation that the half-removal time for the patient's VLDL is within the normal range suggests that the secretion rate of VLDL is not markedly decreased, at least with this particular mutation. If the steady-state assumption is made and the contribution of B-48 to the total apo B detected immunochemically in plasma is arbitrarily set at one-quarter, which is a maximum based on SDS gel electrophoresis, an approximate production rate for the mutant apo B-50 can be calculated. The value obtained, $575 \mathrm{mg} / \mathrm{d}$ would correspond to $\sim 1.1 \mathrm{~g} / \mathrm{d}$ of apoB-100. This value too is within the normal range. The prominence of apoB-50 containing particles even during fat absorption may be a reflection of rapid uptake of chylomicrons by liver with increased secretion of the abnormal VLDL. The very low levels of apoB-50-containing LDL observed in the patient's plasma and the observation that virtually no label is found in the LDL interval after reinfusion of radiolabeled $d<1.006$ $\mathrm{g} / \mathrm{ml}$ lipoprotein suggest that either very little of the abnormal VLDL is processed to LDL or that the lipoproteins formed are removed at a very rapid rate. The absence of the putative LDLreceptor ligand domain from the LDL particles containing the apoB-50 protein would be expected to decrease substantially their removal by the LDL receptor and cause their accumulation in plasma (12). Thus, the low levels of LDL present most likely reflect removal of apoB-50 VLDL particles before they can be converted to LDL. The observation that very little label is present in IDL after reinfusion is consistent with this hypothesis. Our finding of substantial amounts of apoE in the triglyceride-rich particles suggests that the abnormal VLDL may be removed by receptor-mediated endocytosis in which apoE serves as the ligand, such as that involved in the normal hepatic removal of chylomicron remnants. The clearance of abnormal particles by Kupffer cells and macrophages, however, could lead to a similar lipoprotein pattern.

Previously (8) it was shown that the patient's serum produced a precipitin arc with antiserum to $L p(a)$. Using a monoclonal antibody-based ELISA assay specific for $\operatorname{Lp}(a)$ we have confirmed the presence in her serum of the $L p(a)$ antigen, apo(a), although the level measured was low $(0.1 \mathrm{mg} / \mathrm{dl})$. The attachment site of apo(a) to apoB-100 in $\mathrm{Lp}(\mathrm{a})$ is thought to be via an unpaired cysteine residue in one of the kringle- 4 repeats of apo(a) and a cysteine residue in apoB-100 (49). Because this 
residue in apoB-100 has been shown to be in the $\mathrm{COOH}$-terminal region of the protein (Hardman, D. A., and J. P. Kane, unpublished results), which is missing in the patient's apoB (both in her apoB-48 and apoB-50), the apo(a) detected in the patient's serum by this assay probably represents free material unbound to apoB. However, it should be noted that it has recently been postulated that a part of $\mathrm{Lp}(\mathrm{a})$ may be a complex of apo(a) and apoB bound by noncovalent hydrophobic interactions (50).

\section{Acknowledgments}

We wish to thank Dr. Richard Havel for the measurements of apolipoprotein E.

This work was supported by National Institutes of Health grant HL 14237 (Arteriosclerosis Specialized Center of Reseatch) and Training Program in Heart and Vascular Diseases grant HL 07192, by the General Clinical Research Center (5-M01-RR00079), and by a gift from Donald and Susan Schleicher. D. A. Hardman was a recipient of an Achievement Rewards for College Scientists Scholarship.

\section{References}

1. Kane, J. P., D. A. Hardman, and H. E. Paulus. 1980. Heterogeneity of apolipoprotein B: isolation of a new species from human chylomicrons. Proc. Natl. Acad. Sci. USA. 77:2465-2469.

2. Havel, R. J., and J. P. Kane. 1989. The Metabolic Basis of Inherited Disease. 6th ed. C. R. Scriver, A. L. Beaudet, W. S. Sly, and D. Valle, editors. McGraw-Hill Book Co., New York. 1129-1138.

3. Knott, J., R. J. Pease, L. M. Powell, S. C. Wallis, S. C. Rall, Jr, T. L. Innerarity, B. Blackhart, W. H. Taylor, Y. Marcel, R. Milne, D. Johnson, M. Fuller, A. J. Lusis, B. J. McCarthy, R. W. Mahley, B. Levy-Wilson, and J. Scott. 1986. Complete protein sequence and identification of structural domains of human apolipoprotein B. Nature (Lond.). 323:734-738.

4. Yang, C.-Y., S.-H. Chen, S. H. Gianturco, W. A. Bradley, J. T. Sparrow, M. Tanimura, W.-H. Li, D. A. Sparrow, H. DeLoof, M. Rosseneu, F.-S. Lee, Z.-W. Gu, A. M. Gotto, Jr., and L. Chan. 1986. Sequence, structure, receptor-binding domains and internal repeats of human apolipoprotein B-100. Nature (Lond.). 323:738-742.

5. Chen, S.-H., G. Habib, C.-H. Yang, Z.-W. Gu, B. R. Lee, S. A. Weng, S. R. Silberman, S.-J. Cai, J. P. Deslypere, M. Rosseneu, A. M. Gotto, Jr., W.-H. Li, and L. Chan. 1987. Apolipoprotein B-48 is the product of a messenger RNA with an organ-specific in-frame stop codon. Science (Wash. DC). 238:363-366

6. Powell, L. M., S. C. Wallis, R. J. Pease, Y. H. Edwards, T. J. Knott, and J. Scott. 1987. A novel form of tissue-specific RNA processing produces apolipoprotein-B48 in intestine. Cell. 50:831-840.

7. Hardman, D. A., A. A. Protter, J. W. Schilling, and J. P. Kane. 1987 Carboxyl terminal analysis of human B-48 protein confirms the novel mechanism proposed for chain termination. Biochem. Biophys. Res. Commun. 149:1214-1219.

8. Malloy, M. J., J. P. Kane, D. A. Hardman, R. L. Hamilton, and K. B. Dalal 1981. Normotriglyceridemic abetalipoproteinemia: absence of the B-100 apolipoprotein. J. Clin. Invest. 67:1441-1450.

9. Hyams, J., P. Herbert, D. Bernier, A. Saritelli, K. Lynch, and M. Berman 1984. Intestinal steatosis despite B-48 synthesis in a child lacking the B-100 apolipoprotein. Clin. Res. 32:399A. (Abstr.)

10. Takashima, Y., T. Kodama, H. lida, M. Kawamura, H. Aburatani, H. Itakura, Y. Akanuma, F. Takaku, and M. Kawade. 1985. Normotriglyceridemic abetalipoproteinemia in infancy: an isolated apolipoprotein B-100 deficiency. Pediatrics. 75:541-546.

11. Harano, Y., H. Kojima, T. Nakano, M. Harada, A. Kashiwagi, Y. Nakajima, T. H. Hidaka, T. Ohtsuki, T. Suzuki, A. Tamura, T. Fujii, T. Nishimura, T. Ohtaka, and Y. Shigeta. 1989. Homozygous hypobetalipoproteinemia with spared chylomicron formation. Metabolism. 38:1-7.

12. Young, S. G., and M. R. Linton. 1991. Genetic abnormalities in apolipoprotein B. Trends Cardiovasc. Med. 1:59-65.

13. Kane, J. P., and R. J. Havel. 1989. The Metabolic Basis of Inherited Disease. 6th ed. C. R. Scriver, A. L. Beaudet, W. S. Sly, and D. Valle, editors. McGraw-Hill Book Co., New York. 1139-1164.

14. Havel, R. J., H. A. Eder, and J. H. Bragdon. 1955. The distribution and chemical composition of ultracentrifugally separated lipoproteins in human serum. J. Clin. Invest. 34:1345-1353.
15. Schuh, J., G. F. Fairclough, Jr., and R. H. Haschemeyer. 1978. Oxygen mediated heterogeneity of apo-low-density lipoprotein. Proc. Natl. Acad. Sci. USA. 75:3173-3177.

16. Edelstein, C., and A. M. Scanu. 1986. Precautionary measures for collecting blood destined for lipoprotein isolation. Methods Enzymol. 128:151-155.

17. Kane, J. P. 1986. Characterization of apoB-containing lipoproteins. Methods Enzymol. 129:123-129.

18. Stalenhoef, A. F. H., M. J. Malloy, J. P. Kane, and R. J. Havel. 1984 Metabolism of apolipoproteins B-48 and B-100 of triglyceride-rich lipoproteins in normal and lipoprotein lipase-deficient humans. Proc. Natl. Acad. Sci. USA. 81:1839-1843.

19. Contreras, M. A., W. F. Bale, and I. L. Spar. 1983. Iodine monochloride (ICl) iodination techniques. Methods Enzymol. 92:277-292.

20. Chen, G. C., J. P. Kane, and R. J. Hamilton. 1984. Thermal behavior of cores of human serum triglyceride-rich lipoproteins: a study of induced circular dichroism of $\beta$-carotene. Biochemistry. 23:1119-1124.

21. Thrift, R. N., T. M. Forte, B. E. Cahoon, and V. G. Shore. 1986. Characterization of lipoproteins produced by the human liver cell line, HepG2, under defined conditions. J. Lipid Res. 27:236-250.

22. Pullinger, C. R., J. D. North, B. Teng, V. A. Rifici, A. E. R. de Brito, and J. Scott. 1989. The apolipoprotein B gene is constitutively expressed in HepG2 cells: regulation of secretion by oleic acid, albumin, and insulin, and measurement of the mRNA half-life. J. Lipid Res. 30:1065-1077.

23. Nakane, P. K., and A. Kawaoi. 1974. Peroxidase-labeled antibody. A new method of conjugation. J. Histochem. Cytochem. 22:1084-1091.

24. Wong, W. L. T., D. L. Eaton, A. Berloui, B. Fendly, and P. E. Hass. 1990. A monoclonal-antibody-based enzyme-linked immunosorbent assay of lipoprotein(a). Clin. Chem. 36:192-197.

25. Havel, R. J., L. Kotite, J.-L. Vigne, J. P. Kane, P. Tun, N. Phillips, and G. C. Chen. 1980. Radioimmunoassay of human arginine-rich apolipoprotein, apoprotein E. J. Clin. Invest. 66:1351-1362.

26. Hardman, D. A., A. A. Protter, G. C. Chen, J. W. Schilling, K. Y. Sato, K Lau, M. Yamanaka, T. Mikita, J. Miller, T. Crisp, G. McEnroe, R. M. Scarborough, and J. P. Kane. 1987. Structural comparison of human apolipoproteins B-48 and B-100. Biochemistry. 26:5478-5486.

27. Schneider, W. J., U. Beisiegel, J. L. Goldstein, and M. S. Brown. 1982. Purification of the low density lipoprotein receptor, an acidic glycoprotein of 164,000 molecular weight. J. Biol. Chem. 257:2664-2673.

28. Towbin, H., T. Staehelin, and J. Gordon. 1979. Electrophoretic transfer of proteins from polyacrylamide gels to nitrocellulose sheets: procedure and some applications. Proc. Natl. Acad. Sci. USA. 76:4350-4354.

29. Saiki, R. K., D. H. Gelfand, S. Stoffel, S. J. Scharf, R. Higuchi, G. T. Horn, K. B. Mullis, and H. A. Erlich. 1988. Primer-directed enzymatic amplification of DNA with a thermostable DNA polymerase. Science (Wash. DC). 239:487-491.

30. Berg, K., L. M. Powell, S. C. Wallis, R. Pease, T. J. Knott, and J. Scott. 1986. Genetic linkage between the antigenic group $(\mathrm{Ag})$ variation and the apolipoprotein B gene: assignment of the Ag locus. Proc. Natl. Acad. Sci. USA. 78:7367-7370.

31. Wu, M.-J., E. Bütler, R. Bütler, and V. N. Schumaker. 1991. Identification of the base substitution responsible for the $\mathrm{Ag}(\mathrm{x} / \mathrm{y})$ polymorphism of apolipoprotein B-100. Arteriosclerosis and Thrombosis. 11:379-384.

32. Huang, L.-S., J. de Graaf, and J. L. Breslow. 1988. ApoB gene MspI RFLP in exon 26 changes amino acid 3611 from Arg to Gln. J. Lipid Res. 29:63-67.

33. Knott, T. J., S. C. Wallis, R. J. Pease, L. M. Powell, and J. Scott. 1986. A hypervariable region $3^{\prime}$ to the human apolipoprotein B gene. Nucleic Acids Res. 14:9215-9216.

34. Sanger, F., S. Nicklen, and A. R. Couslon. 1977. DNA sequencing with chain-terminating inhibitors. Proc. Natl. Acad. Sci. USA. 74:5463-5467.

35. Knott, T. J., S. C. Wallis, L. M. Powell, R. J. Pease, A. J. Lusis, B. Blackhart, B. J. McCarthy, R. W. Mahley, B. Levy-Wilson, and J. Scott. 1986. Complete cDNA and derived protein sequence of human apolipoprotein B-100. Nucleic Acids Res. 14:7501-7503.

36. Young, S. G., S. T. Hubl, D. A. Chappell, R. S. Smith, F. Claiborne, S. M. Snyder, and J. F. Terdiman. 1989. Familial hypobetalipoproteinemia associated with a mutant species of apolipoprotein B (B-46). N. Engl. J. Med. 320:16041610.

37. Wagner, D., E. Krul, J. Tang, P. Talmud, S. Humphries, and G. Schonfeld 1990. A new truncated form of apolipoprotein $B$ in a kindred with hypobetalipoproteinemia: apoB-54.8. Circulation. 82(Suppl. III):III-424.

38. Collins, D. R., T. J. Knott, R. J. Pease, L. M. Powell, S. C. Wallis, S. Robertson, C. R. Pullinger, R. W. Milne, Y. L. Marcel, S. E. Humphries, P. J. Talmud, J. K. Lloyd, N. E. Miller, D. Muller, and J. Scott. 1988. Truncated variants of apolipoprotein B cause hypobetalipoproteinemia. Nucleic Acids Res. 16:8361-8375.

39. Young S. G S. T. Hubl, R. S. Smith, S. M. Snyder, J. F. Terdiman. 1990 Familial hypobetalipoproteinemia caused by a mutation in the apolipoprotein B gene that results in a truncated species of apolipoprotein B (B-31). J. Clin. Invest. 85:933-942.

40. Talmud, P., L. King-Underwood, E. Krul, G. Schonfeld, and S Humphries. 1989. The molecular basis of truncated forms of apolipoprotein B in 
a kindred with compound heterozygous hypobetalipoproteinemia. J. Lipid Res. 30:1773-1779.

41. Welty, F. K., S. T. Hubl, V. R. Pierotti, and S. G. Young. 1990. A truncated isoform of apolipoprotein B (B67) is associated with hypobetalipoproteinemia and hyperalphalipoproteinemia. Circulation. 82(Suppl. III):III-424.

42. Linton, M. F., V. R. Pierotti, S. T. Hubl, and S. G. Young. 1990. An apo-B gene mutation causing familial hypobetalipoproteinemia analyzed by examining the apo-B cDNA amplified from the fibroblast RNA of an affected subject. Clin. Res. 38:286A. (Abstr.)

43. Tennyson, G. E., C. Gabelli, G. Baggio, C. Bilato, and H. B. Brewer, Jr. 1990. Molecular defect in the apolipoprotein $B$ gene in a patient with hypobetalipoproteinemia and three distinct apoB species. Clin. Res. 38:482A. (Abstr.)

44. Young, S. G., S. T. Northey, and B. J. McCarthy. 1988. Low plasma cholesterol levels caused by a short deletion in the apolipoprotein B gene. Science (Wash. DC). 241:591-593.

45. Pullinger, C. R., E. Hillas, D. A. Hardman, G. C. Chen, J. M. Naya-Vigne, J.-M. Lalouel, R. R. Williams, and J. P. Kane. 1990. A mutation in the apolipo- protein B gene results in a truncated variant, apoB-61, in VLDL and LDL in a kindred with hypobetalipoproteinemia. Circulation. 82(Suppl. III):III-424.

46. Huang, L.-S., M. E. Ripps, S. H. Korman, R. J. Deckelbaum, and J. L. Breslow. 1989. Hypobetalipoproteinemia due to an apolipoprotein B gene exon 21 deletion derived by Alu-Alu recombination. J. Biol. Chem. 264:11394-11400.

47. Graham, L. D., C. R. Pullinger, T. C. Jones, T. J. Knott, and J. Scott 1989. Expression and secretion of apolipoprotein (apo)-B constructs by HepG2 cells. Circulation. 80(Suppl. II):II-466.

48. Kruhl, E. S., M. Kinoshita, P. Talmud, S. E. Humphries, S. Turner, A. C. Goldberg, K. Cook, E. Boerwinkle, and G. Schonfeld. 1989. Two distinct truncated apolipoprotein B species in a kindred with hypobetalipoproteinemia. Arteriosclerosis. 9:856-868.

49. Utermann, G. 1989. The mysteries of lipoprotein(a). Science (Wash. DC) 46:904-910.

50. Trieu, V. N., and W. J. McConathy. 1990. Lipoprotein(a) binding to other apolipoprotein B containing lipoproteins. Biochemistry. 29:5919-5924. 